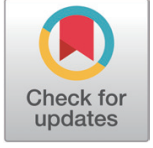

Received: May 24, 2021

Revised: Jul 21, 2021

Accepted: Oct 19, 2021

*Corresponding author

Sunday O. Peters

Department of Animal Science, Berry

College, Mount Berry, Georgia 30149

USA.

Tel: +1-706-368-6919

E-mail: speters@berry.edu

Copyright $\odot 2021$ Korean Society of Animal Sciences and Technology.

This is an Open Access article distributed under the terms of the Creative Commons Attribution

Non-Commercial License (http:// creativecommons.org/licenses/by$\mathrm{nc} / 4.0 /$ ) which permits unrestricted non-commercial use, distribution, and reproduction in any medium, provided the original work is properly cited.

ORCID

Adel S. Khattab

https://orcid.org/0000-0002-2906-4177 Sunday O. Peters

https://orcid.org/0000-0002-0216-926X Adeyemi S. Adenaike

https://orcid.org/0000-0002-9865-6029

Abdel Aziz M. Sallam

https://orcid.org/0000-0002-2019-2682

Mahasan M. Atya

https://orcid.org/0000-0002-9620-1258

Heba AAhmed

https://orcid.org/0000-0003-2444-4952

Competing interests

No potential conflict of interest relevant to this article was reported.

Funding sources

Not applicable.

\section{Phenotypic and genetic parameters of productive traits in Rahmani and Romanov sheep and crossbreds}

\author{
Adel S. Khattab ${ }^{1}$, Sunday O. Peters ${ }^{2 *}$, Adeyemi S. Adenaike ${ }^{3}$, \\ Abdel Aziz M. Sallam ${ }^{4}$, Mahasan M. Atya ${ }^{1}$ and Heba A Ahmed ${ }^{4}$ \\ ${ }^{1}$ Department of Animal Production, Faculty of Agriculture, Tanta University, Central Delta 37512, Egypt \\ ${ }^{2}$ Department of Animal Science, Berry College, Mount Berry, Georgia 30149, USA \\ ${ }^{3}$ Department of Animal Breeding and Genetics, Federal University of Agriculture, Abeokuta 2234, Nigeria \\ ${ }^{4}$ Animal Production Research Institute, Ministry of Agriculture, Cairo 12126, Egypt
}

\section{Abstract}

Data of 651 lambs (68 Romanov, 49 Rahmani, 151 [ㅇ1/2 Rahmani X \$1/2 Romanov) and 383 ( $93 / 4$ Rahmani and 1/4 Romanov]) were collected from Mehalet Mousa Farm, belonging to Animal Production Research Institute from the period of 2009 to 2016 to estimate phenotypic and genetic parameters. The traits studied were birth weight (BW), body weight at four week (BW4), body weight at eight weeks (BW8) and body weight at twelve weeks (BW12) or weaning weight. Least squares analysis of variance shows significance of the effects of breed groups, gender of lambs, birth type; month of birth and year of birth on all traits studied. Rahmani lambs had heavier BW, BW4, BW8 and BW12 while Romanov lambs had the lowest ones. The first generation ( $\$ 1 / 2$ Rhamani $X \quad 1 / 2$ Romanov) had heavier body weights than Romanov and the second generation ( $\$ 3 / 4$ Rahmani X $\$ 1 / 4$ Roamnov). Gender of lambs had highly significant effect on body weights. Males were significantly $(p<0.01)$ heavier than females for all traits studied. Least square means of BW, BW4, BW8 and BW12 for single lambs were $2.69,10.43,13.53$ and $16.10 \mathrm{~kg}$, respectively. Least square means of BW, BW4, BW8 and BW12 for twin lambs were 2.50, 9.37, 12.5 and $15.16 \mathrm{~kg}$, respectively, while least square means of BW, BW4, BW8 and BW12 for triple lambs were 2.09, 7.86, 10.83 and $13.67 \mathrm{~kg}$, respectively. Estimates of direct heritability measured by single trait animal model were $0.14,0.23,0.25$ and 0.26 for BW, BW4, BW8 and BW12, respectively, and the corresponding measured by multi trait animal model were $0.17,0.24,0.32$ and 0.36 for the same traits, respectively. All genetic and phenotypic correlations among different traits studied are positive and significant.

Keywords: Phenotypic, Genetic, Rahmani, Romanov, Breed

\section{INTRODUCTION}

In Egypt, there are several local breeds of sheep such as Rahmani, Ossime, Barki and Seadi. Rahmnai sheep is one of the most common native breeds in Egypt that have the highest body weights and growth rate compare to other Egyptian breeds [1]. As part of effort by the Animal Production 


\section{Acknowledgements}

The authors wish to appreciate all staff of Animal Production Research Institute, Ministry of Agriculture, Kafr El-Sheikh Governorate, Egypt, who were involved in data collection and maintaining the sheep.

\section{Availability of data and material} Upon reasonable request, the datasets of this study can be available from the corresponding author.

\section{Authors' contributions}

Conceptualization: Khattab AS, Sallam AAM, Atya MM, Ahmed HA.

Data curation: Sallam AAM, Atya MM Ahmed HA.

Formal analysis: Peters SO, Adenaike AS,

Ahmed HA.

Methodology: Khattab AS, Peters SO, Adenaike AS, Sallam AAM, Atya MM, Ahmed HA.

Validation: Khattab AS, Peters SO. Investigation: Atya MM, Ahmed HA. Writing - original draft: Khattab AS, Sallam AAM, Atya MM, Ahmed HA.

Writing - review \& editing: Khattab AS, Peters SO, Adenaike AS, Sallam AAM, Atya MM, Ahmed HA.

Ethics approval and consent to participate This article does not require IRB/IACUC approval because there are no human and animal participants.
Research Institute (APRI) to improve sheep production in Egypt, importation of Romanov breed from France was implemented. The present study focused on identifying possibility of introducing the potential productive traits of Romanov sheep to local breeds through crossbreeding. The fixed factors such as breed groups, sex, birth type, month and year of birth of crossbreds affect productive traits [2] beside random genetic factors. Quantification of these fixed factors is very necessary before estimating role of genetic parameters. The objective of the present study was therefore to estimate the phenotypic and genetic parameters responsible for the productive traits (i.e. birth weight [BW], body weight at four weeks [BW4], body weight at eight weeks [BW8] and body weight at weaning or twelve weeks [BW12]) of Romanov and Rahmani sheep and their crosses (\$1/2 Rahmani × $\lesssim 1 / 2$ Romanov) and (\$3/4 Rahmani $\times \precsim 1 / 4$ Romanov). Reliable estimates of phenotypic and genetic parameters can therefore be extended directly to the estimation of breeding values and to the design and optimization of breeding and selection programs for sheep in Egypt.

\section{MATERIALS AND METHODS}

\section{Data and animal management}

The data used in the current investigation were derived from the historical records of two sheep breeds and their crossbreds. As data from the study were derived from historical records of the breeds, hence, IACUC approval was not sought. The animals were housed at Mehallet-Mousa, an experimental station operated by the APRI, Ministry of Agriculture, Kafr El-Sheikh Governorate, a farm situated in the northern portion of the Nile Delta. A record of 903 lambs that were lambed between the periods of 2009 to 2016 was obtained. However, only 651 lambs which have complete data for all the traits and pedigree were used for the analysis in the study. The 651lambs (68

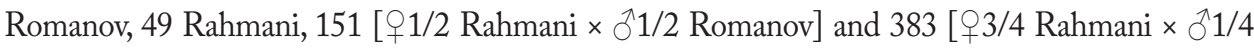
Romanov]) descended from 42 sires and 193 dams with 15.5 progenies per sire and 3.37 progenies per dam on average. Ewes were allowed to mate three times within two years. Animals were housed in semi-closed pens, fed during winter and spring with berseem (Trifolium alexandrinum), during summer and autumn with stubble and berseem hay and/or sorghum fodder (Sorghum bicolor). Concentrate ration supplement of approximately $0.25 \mathrm{~kg} / \mathrm{head}$ per day. BW, BW4, BW8 and BW12 were the traits examined.

\section{Statistical analysis}

In order to determine the significance of fixed effects, data were first analyzed using the GLM procedure of SAS [3] to study the fixed effects of the breed group, lamb gender, type of birth, month of birth and year of birth. Preliminary analysis showed that interaction effects were not significant hence they were removed from the model before considering only main effects in the analysis. The model is given below:

$$
Y_{\mathrm{ijklmn}}=\mu+B_{i}+G_{j}+T_{K}+M_{1}+Y_{m}+e_{i j k l m n}
$$

Where $Y_{\mathrm{ijklmn}}$ is the observed trait on $\mathrm{n}^{\text {th }}$ individual, $\mu$ is the population mean, $\mathrm{B}_{\mathrm{i}}$ is the fixed effect of $i^{\text {th }}$ breed group, $G_{j}$ is the fixed effect of $j^{\text {th }}$ lamb gender, $T_{K}$ is the fixed effect of $k^{\text {th }}$ type of birth, $M_{1}$ is the fixed effect of $\mathrm{t}^{\text {th }}$ month of birth, $\mathrm{Y}_{\mathrm{m}}$ is the fixed effect of $\mathrm{m}^{\text {th }}$ year of birth, $\mathrm{e}_{\mathrm{ijk} k \mathrm{mn}}$ is the random residual errors.

\section{Estimation of heterosis}

For a single mating, heterosis or hybrid vigor cannot be reliably measured because non-genetic 
influences can cause a great deal of variance in a specific trait in a mating. By comparing groups of crossbred and purebred animals, the following formula as defined by Willis [4] can be more accurately used to calculate heterosis.

Heterosis $\%=$ (mean of $\mathrm{F} 1$ offspring - mean of parents $) /$ mean of parents $\times 100 \%$.

\section{Estimation of variance components and genetic parameters}

Variance components were estimated through restricted maximum likelihood procedure, both in single and multi-trait animal models, using the MTDFREML software [5]. In the single trait animal model, genetic parameters were estimated for each single-trait (BW, BW4, BW8 and BW12). The model is described below:

$$
\mathrm{y}=\mathrm{Xb}+\mathrm{Z}_{\mathrm{a}} \mathrm{a}+\mathrm{e}
$$

where $\mathrm{y}$ is the dependent variable vector, $\mathrm{X}$ is the fixed effect incidence matrix associating elements from $\mathrm{b}$ with $\mathrm{y}, \mathrm{b}$ is the fixed effect vector, $\mathrm{Z}_{\mathrm{a}}$ is the random genetic effect incidence matrix associating elements from a with $y, a$ is the vector of random additive genetic effect for each animal and $\mathrm{e}$ is the residual effect vector.

Multi-trait animal model comprises all the four traits together as well as genetic covariance between different traits and errors besides fixed effects. The multi-trait model is represented as follows:

$$
\left[\begin{array}{l}
y_{1} \\
y_{2}
\end{array}\right]=\left[\begin{array}{cc}
X_{1} & 0 \\
0 & X_{2}
\end{array}\right]\left[\frac{b_{1}}{b_{2}}\right]+\left[\begin{array}{cc}
Z_{1} & 0 \\
0 & Z_{2}
\end{array}\right]\left[\frac{a_{1}}{a_{2}}\right]+\left[\frac{e_{1}}{e_{2}}\right]
$$

where $y_{i}$ is the vector of observations for the $i$ th trait, $b_{i}$ is the vector of fixed effects for the $i$ th trait, $a_{i}$ is the vector of random animal effects for the $i$ th trait, $e_{i}$ is the vector of random residual effects for the $i$ th trait, $X_{\mathrm{i}}$ and $\mathrm{Z}_{\mathrm{i}}$ are incidence matrices relating records of the $i$ th trait to fixed and random animal effects, respectively.

Heritability, genetic and phenotypic correlations were calculated as follows:

$$
\begin{gathered}
h^{2}=\frac{\sigma_{a}^{2}}{\sigma_{a}^{2}+\sigma_{e}^{2}} \\
r_{g}=\frac{\operatorname{cov}_{a}}{\sqrt{\sigma_{a_{1}}^{2}+\sigma_{a_{2}}^{2}}}
\end{gathered}
$$

where $b^{2}$ is the heritability of the trait, $\sigma^{2}$ is the additive genetic variance, $\sigma^{2}{ }_{\mathrm{e}}$ is the residual variance, $r_{g}$ is the genetic correlation, $\operatorname{cov}_{a}$ is the additive genetic covariance between trait 1 and trait 2 , $\sigma^{2}{ }_{a 1}$ is the additive genetic variance for trait 1 and $\sigma^{2}{ }_{a 2}$ is the additive genetic variance for trait 2 .

\section{RESULTS AND DISCUSSION}

\section{Overall growth performances}

Unadjusted means, standard deviations (SD) and coefficient of variation (CV\%) of body weight at different ages in the four genotypes of sheep are presented in Table 1. Means of BW) were 2.34, 2.64, 2.60 and $2.56 \mathrm{~kg}$ for Romanov, Rahmani, $1 / 2$ crossbred and 3/4 crossbred, respectively. Means of BW4 were 9.51, 12.24, 11.19 and $10.89 \mathrm{~kg}$ for the four genotypes, respectively. Overall mean 
Table 1. Means, SD and coefficient of variability for body weights at different ages in the four breed groups of sheep

\begin{tabular}{|c|c|c|c|c|c|c|c|c|c|c|c|c|}
\hline & \multicolumn{3}{|c|}{ 3/4 Rahmani x $1 / 4$ Romanov } & \multicolumn{3}{|c|}{ Romanov } & \multicolumn{3}{|c|}{ Rahmani } & \multicolumn{3}{|c|}{ 1/2 Romanov x 1/2 Rahmani } \\
\hline & Mean & SD & $\mathrm{CV} \%$ & Mean & SD & CV\% & Mean & SD & $\mathrm{CV} \%$ & Mean & SD & $\mathrm{CV} \%$ \\
\hline $\mathrm{BW}(\mathrm{kg})$ & 2.34 & 0.49 & 21.24 & 2.64 & 0.47 & 18.11 & 2.60 & 0.43 & 16.54 & 2.56 & 0.46 & 18.27 \\
\hline BW4 (kg) & 9.51 & 4.92 & 51.95 & 12.24 & 3.76 & 30.72 & 11.19 & 2.97 & 26.61 & 10.89 & 3.63 & 40.86 \\
\hline BW8 (kg) & 11.89 & 4.36 & 36.66 & 15.42 & 4.07 & 26.43 & 13.41 & 3.14 & 23.45 & 12.48 & 3.99 & 31.90 \\
\hline BW12 (kg) & 14.66 & 4.84 & 33.07 & 18.00 & 4.60 & 25.55 & 15.54 & 3.44 & 22.20 & 15.32 & 4.80 & 31.30 \\
\hline
\end{tabular}

No. of records $=651$.

$\mathrm{CV}$, coefficient of variation; BW, birth weight; BW4, body weight at one month; BW8, body weight at two months; BW12, body weight at weaning weight.

of BW8 were 11.89, $15.42,13.41$ and $12.48 \mathrm{~kg}$, for the four genotypes, respectively. Unadjusted mean of BW12 were 14.66, 18.00, 15.54 and $14.24 \mathrm{~kg}$, for the four genotypes, respectively. The present results show that body weights at different ages for Rahmani lambs were higher than the other three genotypes. Also, the present results show that the third group (q1/2 Romanov $\times \delta^{\lambda} 1 / 2$ Rahmani) body weight was higher than that of Romanov and the fourth group ( $+3 / 4$ Rahmani $\times$ §1/4 Romanov).

The result of body weight at birth for Romanov lambs was lower than those reported by Abd El Halhm [6] and Ibtsam El-Ksass [7] who worked on another sets of that herd and found that the average BW were 2.50 and $2.90 \mathrm{~kg}$, respectively. Also, the result of body weight at birth for Rahmani lambs was lower than that of Mabrouk et al. [8] who reported average BW of $4.26 \mathrm{~kg}$ for 134 crossbred lambs (1/2 Rahmani $\times 1 / 2$ Finnish).

On the other hand, the present BW4, BW8 and BW12 of Romanov lambs were higher than those reported by some authors who researched on another set of that herd. In this respect, Abd El Halhm [6] worked on Romanov lambs; found that BW1, BW2 and weaning weight (WW) were $6.75,9.57$ and $12.03 \mathrm{~kg}$, respectively. In addition, Ibtsam El-Ksass [7] using another set of Romanov lambs in Egypt, reported that the average BW4, BW8 and BW12 were 7.10, 10.50 and $13.02 \mathrm{~kg}$, respectively.

The WW of Rahmani lambs in this study was higher than result obtained by Oudah [9] who reported average WW of $16.6 \mathrm{~kg}$. Salem and Hammoud [1] reported that the overall mean of WW of Barki and Rahmani lambs were 20.90 and $20.71 \mathrm{~kg}$, respectively. The present WW of crossbred groups (Table 2) were higher than those reported by Mabrouk et al. [8] on 134 crossbred lambs where WW for ( $91 / 2$ Rahmani $\times{ }^{\top} 1 / 2$ Finnish) was $12.72 \mathrm{~kg}$.

The CV\% for body weights at different ages ranged from 21.39 to $51.95 \%$ for Romanov lambs, from 18.11 to 30.72 for Rahmani lambs, from 16.54 to $23.45 \%$ for ( $\$ 1 / 2$ Romanov $\times$ \$1/2 Rahmani) and from 18.27 to $40.86 \%$ for ( $\$ 3 / 4$ Rahmani $\times \$ 1 / 4$ Romanov ). The CV\% for the crossbreds was lower than that obtained by purebred. Therefore, the crossbred had less variation in body weight than purebred. Similar results were reported by Abd El Halhm [6] and Ibtsam ElKsass [7] who worked with another set of that herd and found that the CV \% for body weight traits ranged from $25.86 \%$ to $40.85 \%$, while, the present estimates of CV\% were higher than those reported by Salem and Hammoud [1] who reported results on Barki and Rahmani lambs and Boujenane and Diallo [10] who worked on Sardi sheep which ranged from $12.2 \%$ to $30 \%$.

The BW coefficient of variance was much lower than that of the other traits, suggesting that the environmental impact on BW was lower than that of the other traits. The higher CV percent also indicates greater variation in body weight traits between lambs, and these findings represent a great variation in such economic traits. The variations between the current estimates and those documented by several authors working on various sheep breeds may be due to the fact that these breeds have been raised under different management conditions and controlled by different 
Table 2. Least squares analysis of variance for factors affecting body weight at birth (BW), body weight at one month (BW4), body weight at two months (BW8) and weaning weight (BW12) for the four breed groups of sheep

\begin{tabular}{|c|c|c|c|c|c|}
\hline \multirow{2}{*}{ Sources of variations } & \multirow{2}{*}{ df } & \multicolumn{4}{|c|}{$F$-values } \\
\hline & & BW & BW4 & BW8 & BW12 \\
\hline Between rams & 41 & $1.46^{* *}$ & $1.47^{* \star}$ & $1.97^{\star *}$ & $2.62^{* *}$ \\
\hline Between breed groups & 3 & $2.60^{*}$ & $1.82^{*}$ & $4.75^{\star *}$ & $7.07^{* *}$ \\
\hline Betweeen sex & 1 & $5.50^{* *}$ & $5.23^{\star *}$ & $3.35^{\star *}$ & $3.68^{* *}$ \\
\hline Between type of birth & 2 & $24.47^{\star *}$ & $9.40^{* *}$ & $7.72^{* *}$ & $7.92^{\star \star}$ \\
\hline Between month of birth & 11 & $1.23^{*}$ & $8.25^{\star *}$ & $5.23^{\star *}$ & $4.56^{\star \star}$ \\
\hline Between year of birth & 7 & $0.77^{*}$ & $2.7^{* \star}$ & $2.76^{* *}$ & $2.64^{\star \star}$ \\
\hline Error & 585 & 0.184 & 8.110 & 11.250 & 14.100 \\
\hline
\end{tabular}

${ }^{*} p<0.05,{ }^{* *} p<0.01$

methods, and the statistical analysis models may also vary.

\section{Fixed effects}

Table 2 presents the least square analysis of variance for the effects of breed group, lamb gender, type of birth, month of birth and year of birth on all traits studied. Breed group effect on BW, BW4, BW8 and BW12 were highly substantial.

Average BW were 2.35, 2.61, 2.64 and $2.57 \mathrm{~kg}$ for Romanov, Rahmani, $+1 / 2$ Rahmani × ${ }^{\top} 1 / 2$ Romanov and $\$ 3 / 4$ Rahmani $\times \$ 1 / 4$ Romanov, respectively. Least squares means for BW4 were $9.53,11.19,12.25$ and $8.21 \mathrm{~kg}$, respectively for the same breed groups, respectively. Overall means for BW8 were 11.89, 13.42, 15.42 and $12.49 \mathrm{~kg}$, for the same breed groups, respectively and least squares means for WW were $14.46,15.45,18.00$ and $15.32 \mathrm{~kg}$ for the same groups, respectively. Our results showed that the average BW, BW4, BW8 and BW12 for the crossbred ( $91 / 2$ Rahmani $\times \$ 1 / 2$ Romanov) were higher than the other breed groups. Therefore, it is important to cross between Rahmani ewes with Romanov rams to increase BW and WW. Also, the present results indicate that Rahmani sheep had the highest milking ability, while Romanov had the lowest. This underscores the importance of choosing the maternal breed in any crossbreeding program for intensive sheep production system. On other words, the tested genotypes could rank according to their body weight in a descending sequence as $+1 / 2$ Rahmani $\times 1 / 2$ Romanov, Rahmani, $+3 / 4$ Rahmani × $\$ 1 / 4$ Romanov and then Romanov.

The current findings are close to those documented by several authors in different countries working on different sheep breeds. In this regard, Mabrouk et al. [8] worked on 134 crossbred lambs representing three breed groups (1/4 Finnish $\times$ 3/4 Rahmani [FR], 1/4 Finnish $\times 3 / 4$ Ossimi $[\mathrm{FO}]$ and $1 / 4$ Finnish $\times 3 / 4$ Barki $[\mathrm{FB}])$, found that effect of breed group was significant $(p<0.05)$ for body weight at birth, 6 and 8 week of age, while they were not significant $(p>0.10)$ for body weight at 4 weeks of age. These effects accounted for $25.2 \%, 0.96 \%, 26.7 \%$ and $12.7 \%$ of the total variation in body weights recorded from birth to 8 weeks, respectively. The same authors also found that the crossbred lambs between Finn and Barki had significantly lower body weight than the other two crossbreds at birth (3.56 vs. 4.26 and $4.08 \mathrm{~kg}$, for Finn $\times$ Rahmani and Finn $\times$ Ossimi, respectively) and at 4-weeks of age (6.99 vs. 8.34 and $7.86 \mathrm{~kg}$ for Finn $\times$ Rahmani and Finn $\times$ Ossimi, respectively). The same trend was also observed at 6 weeks of age and 8 weeks of age. The same authors, also, found that the Barki as a dam breed had the lowest milking ability and Rahmani had the highest, while Ossimi ewe was intermediate. Marai et al. [11] also worked on four breeds; 2 pure Egyptian local fat-tailed breed (Ossimi $(\mathrm{O})$ and Rahmani $(\mathrm{R}))$, backcross (1/F Finnish Landrace (F) 3/4 O) and crossbreed (1/4 F 1/F O 1/2 R)), finding that breed type 
affected significantly live weight of lambs at birth and 8,16 and 24 weeks and daily gain during the periods of $0-8$ and $16-24$ weeks of age, in 3 lambing per $2 /$ years system, while only daily gain weight during the periods $8-<16$ weeks was significantly affected, in 2 lambing per 2/year system. Supakorn et al. [12] worked on 29 breed groups and confirmed that pure breeds were sufficient to be used for BW genetic improvement.

Sex effect was significant $(p<0.01)$ for all traits studied. Similar trend was also observed by Mabrouk et al. [8] who worked on crossbred lamb. Oudah [9] with Rahmani sheep; Abd El Halhm [6] worked on Romanov sheep; El-Wakil et al. [13] worked on Barki sheep; Salem and Hammoud [1] worked on Barki and Rahmani sheep. Awad [14] with Awasi sheep and Ibtsam El-Ksass [7] worked on Romanov sheep. In addition, the significant effect of sex on body weights was reported by Ceyhan et al. [15] worked on Sazki sheep in Turkey; Tariq et al. [16] worked on Mengali sheep in Pakistan and Akhtar et al. [17] worked on Buchi sheep in Pakistan.

Males were significantly $(p<0.01)$ heavier than females at birth, BW4, BW8 and BW12 by 0.37 , 1.38, 0.98 and $1.54 \mathrm{~kg}$, respectively. The differences due to sex in BW, BW4, BW8 and BW12 may be due to differences in rate of growth, skeletal development and hormonal function during the prenatal growth period [8]. Ibtsam El-Ksass [7] analyze 820 Romanov lambs in Egypt and found that the average males' weights were 2.62, 6.81, 9.76 and $12.75 \mathrm{~kg}$, for BW, BW4, BW8 and BW12, respectively, while, the corresponding values for females were $2.45,6.74,9.43$ and $12.75 \mathrm{~kg}$, respectively.

Baneh and Hafezian [18] analyzed data on Ghezel sheep and found that average BW and WW for males were heavier than females. They concluded that differences in sexual chromosomes, possibly in the role of growth-related genes, physiological characteristics, endocrine system differences (type and measurement of hormone secretion, especially sex hormones), lead to differences in the growth of animals. Estrogen hormone has a small effect on long bone growth in females in relation to the endocrinal system [8]. That may be one reason why females have a smaller body and a lighter weight relative to male counterparts [19]. The type of birth had an important influence on all the traits studied. Many authors have recorded similar findings $[1,6,7,9,12,14,15,16,19,20]$, in different countries on various sheep breeds.

Least squares means show that the average BW, BW4, BW8 and BW12 for single lambs were heavier than those reported from twin and triple lambs. Least square means of BW, BW4, BW8 and BW12 for single lambs were 2.69,10.43, 13.53 and $16.10 \mathrm{~kg}$, respectively. Least square means of BW, BW4, BW8 and BW12 for twins lambs were 2.50, 9.37, 12.53 and $15.16 \mathrm{~kg}$, respectively, while least squares means of BW, BW4, BW8 and BW12 for triple lambs were 2.09, 7.86, 10.83 and $13.67 \mathrm{~kg}$, respectively. The heavy body weights for single lambs may be due to the fact that single born lambs grew faster than lambs born as twins or triple from birth to weaning. This may be due to the fact that twins or triple lambs share the nutrient during postnatal stage up to weaning. Similar results were reported by many researchers. In this respect, Barghout [19] researched on Neimi lambs in Saudi Arabia, found that BW of single-born lambs exceeded significantly $(p<$ 0.01 ) that of twins. This might be due to the limited uterine space in mothers of twin lambs and inadequate availability of nutrients during pregnancy.

Month and year of birth had a significant effect on BW, BW4, BW8 and BW12 (Table 2). Similar results were reported by many authors working on different breeds of sheep in different countries $[7,8,10,11,12,19]$. The effect of month and year of birth on body weight traits may be due to changes in management practices from year to year, culling old and weak ewes, different feeding, climatic and phenotypic trends.

Breed groups, gender of lambs, type of birth, month of birth and year of birth are the main factors affecting BW, BW4, BW8 and BW12. Therefore, adjusting the productive traits for these 
factors is very necessary for estimation of genetic parameters, breeding values, selection index and genetic trend. Also, Abd El Halhm [6] and Ibtsam El-Ksass [7] worked on Romanov lambs in Egypt concluded that adjusting of the individual records will remove large portion of the nongenetic factors interfere growth performance.

\section{Heterosis effect}

Heterosis is the superiority of a cross over the mid-parent. If two breeds or lines are crossed, then one can expect the progeny to be at the mid-point between the parental means [4]. Heterosis $\%$ of the present studied for $F_{1}$ and $F_{2}$ crossbred are presented in Table 3. Heterosis $\%$ for $F_{1}$ were 5.24\%, 18.24\%, 21.80\% and 19.68\% for BW, BW4, BW8 and BW12, respectively. Heterosis estimates for $\mathrm{F}_{1}$ are positive and increased with increasing age. Heterosis effects are often high when crossing local breed (Rahmani sheep) with foreign breed (Romanov sheep). These results indicated the important of crossing between Rahmani sheep as a local breed with Romanov sheep as a foreign breed to increase body weight at different ages. This is the main objective of the sheep breeder. Estimates of heterosis \% for BW was similar to that reported by many authors. In this respect, Willis [4] concluded that heterosis $\%$ for BW and pre-weaning growths were 6 and $7 \%$ respectively. Heterosis\% for the second generation were $3.63 \%,-13.96 \%,-1.34 \%$ and $0.00 \%$ for BW, BW4, BW8 and BW12, respectively. The present results indicated that heterosis decline in the $\mathrm{F}_{2}$ generation for BW and negative for BW4 and BW8 and zero for BW12. Similar results were reported by Willis [4] who stated that heterosis declines in the $\mathrm{F}_{2}$ generation to half of that in the $\mathrm{F}_{1}$. On the other hand, Elshennawy et al. [20] analyzed 1693 lambs data and reported that increase of Romanov blood from $25 \%$ to $50 \%$ had no significant change in mature weight, rate of maturity and instantaneous growth rates at 2, 6 and 12 months of age. Negative heterosis is connected with nonadditive genes and their oxidative phosphorylation [21] which cause unfavourable impacts on production performance of animals. Heterosis reduces in later generations after F1 due to segregation and recombination losses [22]. However, it has been recommended that criss-cross breeding programme preserves positive heterosis [23].

\section{Genetic parameters}

Estimates of variance components from univariate (Model 1) and multi-trait animal model (Model 2) for BW, BW4, BW8 and BW12 are given in Tables 4 and 5. Estimates of $h^{2}$ for BW was small (0.14 and 0.17) as estimated from Model 1 and Model 2 respectively. Similar results were reported by Abd El Halhm [6] (0.17) and Ibtsam El-Ksass [7] (0.18) worked on Romanov lambs in Egypt. On the other hand, our estimates were lower than the estimate reported by Rosati et al. [24] (0.27). The small estimate of heritability for BW may be due to importance of random environmental effect on variability of the observation and due to the categorical expression of the trait [25]. Accordingly, the small estimate of $\mathrm{h}^{2}$ for BW, suggest that improvement of BW only by selection will be difficult [6]. However, improvement of BW by improving management and feeding may

Table 3. Heterosis \% for birth weight (BW), body weight at four weeks (BW4) body weight at eight weeks (BW8) and body weight at twelve weeks (BW12)

\begin{tabular}{lrr}
\hline \multirow{2}{*}{ Traits } & \multicolumn{3}{c}{ Heterosis \% } \\
\cline { 2 - 3 } & F1 & F2 \\
\hline BW & 5.24 & 3.63 \\
BW4 & 18.24 & -13.96 \\
BW8 & 21.80 & -1.34 \\
BW12 & 19.68 & 0.00 \\
\hline
\end{tabular}


Table 4. Estimate of variance components by single trait animal model for birth weight (BW), body weight at one month (BW4), body weight at two months (BW8) and weaning weight (BW12)

\begin{tabular}{lcccc}
\hline \multicolumn{1}{c}{ Parameter } & BW & BW4 & BW8 & BW12 \\
\hline$\sigma^{2}{ }_{a}$ & 0.258 & 2.000 & 3.130 & 3.276 \\
$\sigma^{2}$ & 0.164 & 6.660 & 9.245 & 9.150 \\
$\sigma_{p}^{2}$ & 0.189 & 8.660 & 12.376 & 12.426 \\
$h^{2} \pm \mathrm{SE}$ & $0.14 \pm 0.07$ & $0.23 \pm 0.09$ & $0.25 \pm 0.09$ & $0.26 \pm 0.09$ \\
\hline$\sigma_{\mathrm{a}}^{2}, \sigma_{\mathrm{e}}^{2}, \sigma_{\mathrm{p}}^{2}$ and $\mathrm{h}^{2}$ are additive genetic variance, residual variance, phenotypic variance and direct heritability respectively.
\end{tabular}

Table 5. Estimates of heritability (bolded) on diagonal, genetic correlations (below diagonal) and phenotypic correlations (above diagonal) among different traits studied

\begin{tabular}{lcccc}
\hline \multicolumn{1}{c}{ Traits } & BW & BW4 & BW8 & BW12 \\
\hline BW & $0.17 \pm 0.05$ & 0.75 & 0.80 & 0.89 \\
BW4 & $1.00 \pm 0.20$ & $0.24 \pm 0.08$ & 0.82 & 0.90 \\
BW8 & $1.00 \pm 0.21$ & $1.00 \pm 0.10$ & $0.32 \pm 0.09$ & 0.92 \\
BW12 & $0.75 \pm 0.09$ & $0.80 \pm 0.03$ & $0.84 \pm 0.09$ & $0.36 \pm 0.1$ \\
\hline
\end{tabular}

be more useful. Jalil-Sarghale et al. [26] also found that for BW, direct $\mathrm{h}^{2}$ estimate was 0.062 . Genetic and environmental factors, such as the placenta and the fetal nutrition of a dam, affect fetal development. Therefore, environmental factors affect the growth of dams, especially the quality and quantity of food and the storage by dam of food may affect the growth of the embryo. Supakorn et al. [12], on the other hand, found that the BW value for $\mathrm{h}^{2}$ was 0.36 . They concluded that the population had moderate differences in the direct genetic additive effect for BW and only for BW on the positive characteristics of genetic mothering abilities. Heritability estimates for BW4, BW8 and BW12 were $0.23,0.25$ and 0.26, respectively as estimated from Model 1 and were 0.24, 0.32 and 0.36 , respectively as estimated by Model 2 . These values showed that $\mathrm{h}^{2}$ estimates for body weight increased with increasing age. Abd El Halhm [6] worked with Romanov lambs in Egypt and concluded same results and found that $\mathrm{h}^{2}$ estimates for BW, BW4, BW8 and BW12 were 0.17, $0.27,0.17$ and 0.20 , respectively. According to the moderate estimates of $\mathrm{h}^{2}$ for BW4, BW8 and BW12 by the two models, it indicated that improvement of BW4, BW8 and WW by selection could give good results in short period and this can be used for early selection of lambs. The current estimates are close to those published in different countries by several authors working on various sheep breeds.

Ibtsam El-Ksass [7] studied Romanov sheep in this respect and found that direct estimates of heritability for BW and WW were 0.22 and 0.25 , respectively. Oudah [9] stated that direct heritability were 0.33 and 0.48 , respectively for BW and WW on Rahmani sheep. Abegaz et al. [27] discovered that direct heritability for BW and WW was 0.272 and 0.259 , respectively on Horro sheep in Ethiopia. They concluded that through well-designed selection programs, selection would be a successful means of genetic enhancement for early growth traits for the Horro sheep.

Hanford et al. [28] worked on Targhee sheep and found that $\mathrm{h}^{2}$ for BW and WW were 0.25 and 0.22, respectively. Working on Chokia sheep, El-Wakil et al. [13] found that heritability estimates for BW and WW were respectively 0.32 and 0.41. With Arabi sheep, Shokrollahi and Baneh [29] recorded that direct heritability was 0.42 and 0.38 respectively for BW and WW. Our estimates of $\mathrm{h}^{2}$ for BW4, BW8 and BW12, on the other hand, are greater than those estimated by many authors. Boujenane and Kansari [30] found that for BW, BW4, BW8 and BW12, direct heritability was $0.05,0.02$ and 0.06 , respectively. The same authors have concluded that a much lower proportion of genetic variation in Timahdite lambs was shown by the low $\mathrm{h}^{2}$ body weight estimates, implying 
that slow genetic improvement can be obtained from selection under the extensive production system. Ekiz et al. [31] worked on Merino sheep; 0.0462 and 0.0255 were found to be direct $h^{2}$ for BW and WW. They concluded that selection based on the own performance of ewes could lead to slow genetic change, Abd El Halhm [6] worked on Romanov lambs in Egypt and reported that the low $\mathrm{h}^{2}$ body weight estimates at two months $(0.17)$ could be due to the fact that lambs did not receive creep feeding and were raised in a poor nutritional environment in general, resulting in lambs not expressing their genetic potential. Jalil-Sarghale et al. [26] found that there were 0.062 and 0.12, respectively, direct $h^{2}$ for BW and WW. On Buchi sheep, Akhtar et al. [17] reported that $h^{2}$ estimates were 0.194 and 0.153 for BW and WW, respectively.

Variance and covariance analysis of the Multivariate Trait Animal Model (MTAM) was performed on Rahmani, Romanov and crossbred data to derive estimates of direct additive genetic correlation (rg) and phenotypic correlation (rp) between the different traits studied, as shown in Table 5.

Estimates of genetic correlations between BW and each of BW4, BW8 and BW12 were significantly positive $(p<0.01)$ and being $1.00,1.00$ and 0.75 respectively. Genetic correlation between BW4 and each of BW8 and BW12 were 1.00 and 0.84 respectively. Also, genetic correlation between BW8 and BW12 was 0.84 . The present results indicated that selection for heavier weights of birth in lambs will cause a correlated increase in BW4, BW8 and BW12. Also, positive genetic correlations found between BW4 and other traits, implies that BW4 could be considered in selection program when we want to improve WW at two months. It is important to note that the genes which affect BW also affect BW4, BW8 and BW12. Many authors who have worked on various breeds of sheep in different countries have recorded similar findings.

Abegaz et al. [27] while working on Horro sheep found that genetic correlation between BW, WW, BW6 and BW12 were positive and ranged from 0.306 to 0.979 . They concluded that through well-designed selection programs, selection would be an efficient means for genetic improvement of early growth traits in the Horro sheep.

Boujenane and Kansari [30] studied Timahdite sheep in Morocco and found that the direct genetic additive correlations between BW, BW70 and BW90 days ranged from 0.28 to 0.91 days and were positive. The same authors concluded that in other weights, selection for one of the weights could result in genetic improvement.

The genetic correlation between BW and WW was 0.52 as reported by Hanford et al. [28]. The moderate estimate of direct genetic correlation indicates that the genetic merit of BW in animals with above-average WW may appear to be above average. Abd El Halhm [6] worked on Romanov lambs in Egypt, stating that at one and two months of age, the genetic correlation between BW and body weight was 0.44 and 0.22 , respectively. The author concluded that selection for body weight at one month will increase body weight at two months of age. Jalil-Sarghale et al. [26] while working on Baluchi sheep in Iran, found that the genetic correlation between BW and WW was 0.75, and indicated that BW and WW could be genetically managed same way. Thus, selection can be performed based on one of them. Also, Ibtsam El-Ksass [7] reported on Romanov sheep in Egypt and found that the genetic correlations between BW, BW1, BW2 and WW were positive, highly significant and ranged from 0.15 to 0.62 . The author suggested that selection for heavier weights of birth in lambs causes a correlated increase in body weight at one, two months and at WW.

Estimates of phenotypic correlation were positive, highly significant and ranged from 0.75 to 0.92 for all body weights (Table 5) and were lower than their corresponding genetic correlation. Higher genetic correlations than phenotypic correlations may be due to small number of observation and adjustment of non-genetic effects. The present estimates agree with those obtained on other breeds. In this respect, Oudah [9] analyzed 2417 Rahmani sheep in Egypt and found 
that phenotypic correlations between BW, WW, BW6 were positive and ranged from 0.712 to 0.992. Abegaz et al. [27] worked on Horro sheep and found that phenotypic correlations between BW,WW, BW6 and BW12 were positive and ranged from 0.116 to 0.729. El-Awady [32] worked with Barki sheep in Egypt and found that the phenotypic correlations between BW, WW, BW6 and BW12 were positive and ranged from 0.43 to 0.82 . Boujenane and Kansari [30] worked with Timahdite sheep in Morocco and found that the phenotypic correlations between BW, BW70 and BW90 days were positive and ranged from 0.28 to 0.77 .

\section{CONCLUSION}

The study results suggest that breed groups, lamb gender, type of birth, month and year of birth have a highly significant impact on BW, BW4, BW8 and WW. Body weight traits in the herd of Rahmani tended to be better than the other genotypes. While Romanov lambs had the lowest body weight at different ages. Crossbred lamb ( $\$ 1 / 2$ Rahmani $\times \delta 1 / 2$ Romanov) was higher than Romanov lambs and ( 9 3/4 Rahmani $\times 1 / 4$ Romanov). Therefore it is important to use Rahmani sheep as a local breed and grading it with foreign breeds such as Romanov to increase body weight at different ages. Male lambs had heavier BW, BW4, BW8 and BW12 than female lambs $(p<0.10)$. There were heavier $(p<0.01)$ lambs born singles than born twins and triples. The month and year of lambing had a significant influence on all of the traits examined. The changes in management conditions and feeding quality over the years can explain these impacts. The estimates of medium heritability recorded by single and multi-trait animal models have shown that direct selection based on growth traits could be successful. Positive estimates of genetic correlation obtained from the multi-trait animal model indicate that birth and WW selection will contribute to a rise in body weight at later ages. The present results indicated that improvement of environmental factors such as feeding system, recording system, methods of suckling and using better methods for suckling will improve growth traits especially weight at birth and body weight at one month, which can be used for early selection.

\section{REFERENCES}

1. Salem M, Hammoud MH. Estimation of variance components and heritability's of pre-weaning growth traits of Barkai and Rahmani sheep. Egypt J Anim Prod. 2017;54:1-8.

2. Barazandeh A, Moghbeli SM, Vatankhah M, Mohammadabadi M. Estimating non-genetic and genetic parameters of pre-weaning growth traits in Raini Cashmere goat. Trop Anim Health Prod. 2012;44:811-7. https://doi.org/10.1007/s11250-011-9971-5

3. SAS Institute. SAS/STAT software. Release 6. Cary, NC: SAS Institute; 2002.

4. Willis MB. Dalton's introduction to practical animal breeding. 4th ed. Oxford: Blackwell Science; 1998.

5. Boldman KG, Kriese LA, Van Vleck LD, Van Tassel CP, Kachman SD. A manual for use of MTDFREML: a set of programs to obtain estimates of variances and covariances [DRAFT]. Washington DC: United States Department of Agriculture, Agriculture Research Service; 1995.

6. Abd El Halhm HAEHM. Genetic evaluation on sheep performance in Egypt [Master's thesis]. Mansoura, Egypt: Mansoura University; 2008.

7. Ibtsam El-Ksass F. Phenotypic and genetic trends for some productive traits in Romanov sheep. [Master's thesis]. Tanta, Egypt: Tanta University; 2018.

8. Mabrouk MNS, Kadry AEH, Oksh AE, El-Fiky FA. Studies on some factors affecting growth 
of crossbred lambs during the sulking period. Paper presneted at 11th International Congress for Statistics, Computer Science, Social and Demographic Research; 1986; Cairo, Egypt.

9. Oudah EZ. Genetic parameters and sire evaluation for growth traits in Egyptian Rahmani lambs.J Agric Sci Mansoura Univ Egypt. 2002;27:927-43.

10. Boujenane I, Diallo IT. Estimates of genetic parameters and genetic trends for pre-weaning growth traits in Sardi sheep. Small Rumin Res. 2017;146:61-8. https://doi.org/10.1016/ j.smallrumres.2016.12.002

11. Marai IFM, Daader AH, Bahgat LB. Performance traits of purebred Ossimi and Rahmani lambs and their crosses with Finnsheep born under two accelerated mating systems. Arch Anim Breed. 2009;52:497-511. https://doi.org/10.5194/aab-52-497-2009

12. Supakorn C, Pralomkarn W, Anothaisinthawee S. Estimation of genetic parameters and genetic trends for weight and body measurements at birth in sheep populations in Thailand. Songklanakarin J Sci Technol. 2013;35:1-10.

13. ElWakil SI, ElSayed M, Ahmed AM, Sadek RR, Nigm AA. Genetic and phenotypic parameters of birth, weaning and yearling body weights of Barki sheep raised in the North Western Coast of Egypt. Egypt J Anim Prod. 2009;46:43-52.

14. Awad H. Genetic study on Saidi sheep [Ph.D. dissertation]. Mansoura, Egypt: Mansoura University; 2018.

15. Ceyhan A, Sezenler T, Erdoğan İ. The estimation of variance components for prolificacy and growth traits of Sakız sheep. Livest Sci. 2009;122:68-72. https://doi.org/10.1016/j.livsci.2008.07.030

16. Tariq MM, Bajwa MA, Abbas F, Waheed A, Bokhari FA, Rafiq M. Heritability of pre-weaning growth performance traits in Mengali sheep in (Balochistan) Pakistan. Int J Biodivers Conserv. 2010;2:284-8. https://doi.org/10.5897/IJBC.9000073

17. Akhtar M, Javed K, Abdullah M. Single trait analysis for preweaning growth traits of Buchi sheep in Pakistan. J Anim Plant Sci. 2014;24:693-9.

18. Baneh H, Hafezian SH. Effects of environmental factors on growth traits in Ghezel sheep. Afr J Biotechnol. 2009;8:2903-7.

19. Barghouth AA. A study on birth weight and pre-weaning mortality of Neimi lambs in Saudi Arabia. Egypt J Anim Prod. 1999;36:43-50. https://doi.org/10.21608/ejap.1999.110378

20. Elshennawy MA, Almahdy H, Osman MA. Growth characteristics of Romanov and Romanov-Rahmani crossbred lambs in Egypt. Egypt J Anim Prod. 2004;41:73-84. https://doi. org/10.21608/ejap.2004.108048

21. Mai C, Wen C, Xu Z, Xu G, Chen S, Zheng J, et al. Genetic basis of negative heterosis for growth traits in chickens revealed by genome-wide gene expression pattern analysis.J Anim Sci Biotechnol.2021;12:52. https://doi.org/10.1186/s40104-021-00574-2

22. Sendros DM. Genetic factors affecting milk production, growth and reproduction traits in Bos indicus $x$ Bos taurus crosses in Ethiopia [Ph.D. dissertations]. Bloemfontein, South Africa: University of Free State; 2002.

23. Wakchaure R, Ganguly S, Praveen PK, Sharma S, Kumar A, Mahajan T, et al. Importance of heterosis in animals: a review. Int J Adv Eng Technol Innov Sci. 2015;1:1-5.

24. Rosati A, Mousa E, Van Vleck LD, Young LD. Genetic parameters of reproductive traits in sheep. Small Rumin Res. 2002;43:65-74. https://doi.org/10.1016/S0921-4488(01)00256-5

25. Falconer DS, Mackay TFC. Introduction to quantitative genetics. 4th ed. Harlow: Longman; 1996.

26. Jalil-Sarghale A, Kholghi M, Moradi Shahrebabak M, Moradi Shahrebabak H, Mohammadi $\mathrm{H}$, Abdollahi-Arpanhi R. Model comparisons and genetic parameter estimates of growth traits 
in Baluchi sheep. Slovak J Anim Sci. 2014;47:12-8.

27. Abegaz S, Negussie E, Duguma G, Rege JEO. Genetic parameter estimates for growth traits in Horro sheep. J Anim Breed Genet. 2002;119:35-45. https://doi.org/10.1046/j.14390388.2002.00309.x

28. Hanford KJ, Van Vleck LD, Snowder GD. Estimates of genetic parameters and genetic change for reproduction, weight, and wool characteristics of Targhee sheep. J Anim Sci. 2003;81:63040. https://doi.org/10.2527/2003.813630x

29. Shokrollahi B, Baneh H. (Co)variance components and genetic parameters for growth traits in Arabi sheep using different animal models. Genet Mol Res. 2012;11:305-14. https://doi. org/10.4238/2012.February.8.5

30. Boujenane I, Kansari J. Estimates of (co)variances due to direct and maternal effects for body weights in Timahdite sheep. Anim Sci. 2002;74:409-14. https://doi.org/10.1017/ S1357729800052553

31. Ekiz B, Özcan M, Yilmaz A, Ceyhan A. Estimates of phenotypic and genetic parameters for ewe productivity traits of Turkish Merino (Karacabey merino) sheep. Turk J Vet Anim Sci. 2005;29:557-64.

32. El-Awady HG. Different animal models for estimating genetic parameters of Barki sheep in Egypt.J Am Sci. 2011;7:882-7. 